\title{
[Artigo retratado] Aporte e decomposição de serapilheira em um fragmento de mata atlântica (floresta ombrófila) em Alagoas, Brasil
}

\section{Antonio Marcos Delfino de Andrade ${ }^{1}$, Rayonil Gomes Carneiro², José Marcelo Lopes Júnior², Carlos Alexandre Santos Querino ${ }^{3}$ e Marcos Antonio Lima Moura 4}

\author{
${ }^{1}$ Universidade Federal do Oeste do Pará. Unidade Tapajós. Rua Ver Paz S/No. \\ Bairro Salé. Santarém-PA, Brasil (CEP 68035-1. v. 2-mail: \\ marcoslaba33@gmail.com. \\ ${ }^{2}$ Instituto Nacional de Pesquisas Espaciais. Centro de ciên as do Sistema \\ Terrestre. Av. dos Astronautas, 1758. Jardim da Grania. S o ys dos Campos-SP, \\ Brasil (CEP 12227-010). \\ ${ }^{3}$ Universidade Federal do Amazonas. Rua 29 de ag ${ }^{+}$, $>$Campus Vale do Rio \\ Madeira. Humaitá-AM, Brasil (CEP 69800-000). \\ ${ }^{4}$ Universidade Federal de Alagoas. Instituto de rênc as Atmosféricas. Av. Lourival \\ Melo Mota, S/№. Tabuleiro do Martins. Mac ơ-A Brasil (CEP 57072-900).
}

Resumo. 0 presente estudo foi desenvolvi $0 \mathrm{e}$ unn fragmento de floresta ombrófila aberta que so any lve com uma transição para a Floresta Estacional S nideumal, no Município de Coruripe, Estado de Alagoas, Brasil, tre novembro/2009 e fevereiro/2015, com o objetim de avaliar os efeitos das alterações climáticas sobre os rocessos de produção e decomposição de serapilh 'ira $\mathrm{O}$ ar orte de serapilheira total e acumulada foram men traa utilizando-se 10 coletores cada, todos instalados aleator men \&, endo um coletado mensalmente e outro trimestra len lambé $h$ foram realizadas medições no local de precipi çầ raa.çẫo solar global e velocidade do vento em uma torre icrometeorológicas de $26 \mathrm{~m}$ de altura (latitude $10^{\circ} 00$ c. lon itude $36^{\circ} 17^{\prime} 60^{\prime \prime} \mathrm{W}$; alt. $160 \mathrm{~m}$ ). Observou-se que as ari vo meteorológicas apresentaram uma variação sazonal $b$ stante forte associadas às estações seca e chuvosa. A produção hédia mensal de serapilheira durante o período observado foi de $0,618 \mathrm{Mg} \mathrm{ha}^{-1}$, sendo novembro e julho os meses de maior e menor aporte. As variáveis precipitação, radiação solar e velocidade do vento indicaram correlação moderada e inversamente proporcional com a produção de serapilheira. A serapilheira acumulada mostrou padrão sazonal, com maior acúmulo na estação seca, mas o aproveitamento da serapilheira bem como o tempo de meia-vida é relativamente muito abaixo do esperado para ecossistemas tropicais similares.

Recebido $14 / 09 / 2020$

Aceito

29/08/2021

Publicado

$31 / 08 / 2021$

Acesso aberto

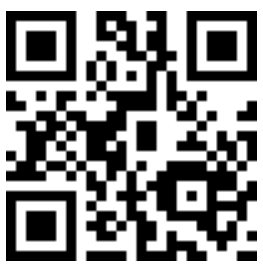

ORCID

(D) 0000-0002-2075-7890

Antonio Marcos

Delfino de Andrade

ISSN 2359-1412/RBGAS-2020-0135/2021/8/19/39/1219

Rev. Bras. Gest. Amb. Sustent.

http://revista.ecogestaobrasil.net 